\title{
Repeater Device
}

National Cancer Institute

\section{Source}

National Cancer Institute. Repeater Device. NCI Thesaurus. Code C50139.

An electronic device designed to receive a signal, amplify it, and resend it. 